\title{
RITUAL E TEATRO NA CULTURA POPULAR
}

Maria Laura Viveiros de Castro Cavalcanti (UFRJ)

O artigo aborda a relação entre antropologia e teatro, mais especificamente entre a noção antropológica de ritual e a ideia de teatro das artes cênicas. Buscam-se as interinfluências, as semelhanças e diferenças marcantes entre ritual e teatro, tomando por foco a cultura popular, em especial o carnaval das escolas de samba e o bumba meu boi. Enfatizam-se as diferentes formas da temporalidade nos processos rituais, bem como a qualidade de performance que modifica as formas mais usuais e descritivas de compreensão da cultura popular. ${ }^{1}$

RITUAL; TEATRO; ANTROPOLOGIA; PERFORMANCE; CULTURA POPULAR; CARNAVAL; BOI-BUMBÁ.

CAVALCANTI, Maria Laura Viveiros de Castro. Ritual e teatro na cultura popular. Textos escolhidos de cultura e arte populares, Rio de Janeiro, v.12, n.1, p. 7-22, mai. 2015. 


\section{RITUAL AND THEATRE IN POPULAR CULTURE}

Maria Laura Viveiros de Castro Cavalcanti (UFRJ)

The article discusses the relationship between anthropology and theater, more specifically between the anthropological notion of ritual and the idea of theater from the performing arts. We search the interinfluences, the similarities and striking differences between ritual and theater, focusing on popular culture, especially the carnival of samba schools and the bumba meu boi. We emphasize the different forms of temporality in ritual processes and the quality of performance that modifies the most common and descriptive ways of understanding popular culture.

RITUAL; THEATRE; ANTHROPOLOGY; PERFORMANCE; POPULAR CULTURE; CARNAVAL; BOI-BUMBÁ.

CAVALCANTI, Maria Laura Viveiros de Castro. Ritual e teatro na cultura popular. Textos escolhidos de cultura e arte populares, Rio de Janeiro, v.12, n.1, p. 7-22, mai. 2015. 
Esta é uma conversa entre antropologia e teatro, mais especificamente entre a noção antropológica de ritual e a ideia de teatro das artes cênicas. O ponto de partida está nos aspectos marcantes que ritual e teatro têm em comum. Ambos requerem hora e lugar certos para existir, exigem interações corporais plenas, constituem encontros diretos entre pessoas. Sua natureza expressiva requer duração temporal especial, dotada de materialidade e concretude, e ambos pedem ensaios, muito trabalho preparatório. Essas semelhanças, entretanto, convivem com diferenças significativas. Adotando o enfoque antropológico, buscamos essas semelhanças e diferenças tomando por foco o ambiente das culturas populares.

Os estudos antropológicos do ritual se confundem com a própria constituição da disciplina, e vale indicar, de modo introdutório, a centralidade desse tema na construção da própria visão antropológica do humano.

\section{RITUAL E ANTROPOLOGIA}

Desde o último quartel do século XIX, quando a antropologia se inicia, a noção de ritual faz par com aquela de mito, recobrindo condutas e crenças que causavam estranheza ao homem europeu moderno. Dessa forma ambivalente, a um só tempo atraente e repulsiva, uma ampla gama de condutas e pensamentos simbólicos e expressivos foi acolhida pela reflexão antropológica. Ritos e mitos tinham certamente a nobreza das origens civilizatórias ocidentais os gregos tinham, afinal, não só seus mitos, mas também seus ritos, como fez ver Jane Harrison (1908) em estudo clássico. Mas eram, ao mesmo tempo, um indício da natureza primitiva dos povos com que esse mesmo europeu se relacionava, e o fazia de modo cada vez mais intenso com a expansão mundial da economia capitalista.

Entretanto, esse estranhamento das formas de ser dos grupos humanos seguia seu curso também dentro da própria sociedade europeia e, junto com a violenta história do século $X X$, ia desestabilizando certezas fundadas numa espécie de fé na superioridade de uma forma da racionalidade que se acreditava caracterizar o pensamento científico, por oposição às formas mágicas, míticas ou religiosas do pensamento humano. Em especial, as descobertas da psicanálise freudiana acerca do psiquismo individual, ao estabelecer de modo notável a natureza sempre interior da alteridade e da heterogeneidade nos processos de construção de identidades, transformaram a própria noção de humano e, com isso, a ideia de cultura.

A alteridade cultural investigada pela antropologia a princípio nos "outros", "os primitivos", foi servindo, assim, para transformar gradualmente a pró- 
pria visão que tinham de si mesmas as sociedades de onde partiam os estudos antropológicos, que se consideravam referências civilizatórias.

Nesse percurso se construiu a forma de conhecer característica da antropologia. Em linhas gerais, o modelo clássico da pesquisa antropológica estabeleceu a necessidade da convivência por longo tempo com o grupo pesquisado, expondo o pesquisador a formas de agir e de pensar diferentes das suas: a pesquisa de campo etnográfica. No correr dessa experiência, uma espécie de imersão prolongada em um modo de viver distinto, o universo de referências culturais usuais se relativizaria, e se iniciaria, então, a possibilidade da compreensão de uma nova e diferente visão de mundo. O resultado mais palpável dessa empreitada constituiu as etnografias detalhadas e densas, portadoras de grande consistência e originalidade teórica para a disciplina, que com elas encontrou seu nicho entre as humanidades. Resultado menos palpável, mas não menos relevante, foi a constatação de que esse tipo de pesquisa, que produz o conhecimento ou a compreensão do diferente, transforma também o próprio pesquisador. Na investigação antropológica, um sujeito pesquisa outros sujeitos que se afetam mutuamente. Numa formulação feliz do antropólogo Clifford Geertz (1973a), o resultado seria a ampliação do nosso repertório de possibilidades culturais, o alargamento do universo do discurso humano.

Esse caminho foi certamente feito de muitos debates e controvérsias, porém o ponto relevante para nossos propósitos foi o estabelecimento da natureza essencialmente simbólica da sociedade humana e do ser humano de modo geral. O texto mais potente nessa direção, pelo alcance de argumentação, é o livro Culture and practical reason, de Marshall Sahlins (1976), que afirma a centralidade dos processos de simbolização na produção da espécie humana e de sua natureza social. Também Clifford Geertz (1973b), no ensaio O impacto do conceito de cultura sobre o conceito de homem, estabeleceu a cultura como constitutiva da própria evolução milenar da espécie humana. Para ele, cultura constitui-se das redes de significados construídas por nós mesmos e nas quais estamos sempre imersos. Desse modo, a variedade, complexidade e multiplicidade das expressões simbólicas emergiram no centro da cena antropológica.

\section{RITUAL E INTENSIFICAÇÃO DA EXPERIÊNCIA}

A noção de ritual ganhou com isso nova plasticidade. ${ }^{2}$ Em uma acepção muito ampla, podemos hoje compreender por ritual a dimensão expressiva, simbólica e comunicativa de toda conduta humana. Ritual, nesse sentido, funciona como um adjetivo, a qualificar a própria natureza da conduta humana, como um sinônimo da ideia de ação simbólica. O sociólogo Erving Goffman (1975), por 
exemplo, em seu estudo $A$ representação do eu na vida cotidiana observou de modo arguto e detalhado toda a ritualização envolvida nas mais diárias interações face a face. Nessas interações, nos diz ele, nos representamos para o outro e tentamos com isso controlar de algum modo a imagem que queremos que o outro tenha a nosso respeito. E vice-versa. Somos, em sua visão arguta e um tanto obsessiva, todos atores nesse sentido propriamente teatral da encenação, envolvidos num jogo interativo sem fim. A antropóloga Mary Douglas, por sua vez, em seu livro Pureza e perigo (1976), chamou a atenção para a natureza ritual e criativa dos pequenos gestos de uma dona de casa inglesa em sua faina cotidiana de "arrumar a casa" ou mesmo para a natureza ritual do cardápio tido como adequado a cada um dos dias da semana: "o que comeremos no próximo almoço de domingo?" (DOUGLAS, 2004).

Ritual, porém, tem também um sentido mais estrito, sobre o qual nos deteremos aqui. Como já observaram DaMatta (1979) e Tambiah (1985), toda sociedade humana demarca de algum modo momentos extraordinários em contraponto à rotina da vida coletiva. Esses momentos, percebidos pelos que os vivem como excepcionais, são chamados de rituais pela antropologia, porque neles a dimensão coletiva da experiência social se intensifica e parece mesmo palpável. Essa intensidade é produzida por um agregado de condutas e ações simbólicas que podem abranger uma ampla gama de qualidades emocionais - o festivo, o celebrativo, o cerimonial, o fúnebre, entre tantos outros. ${ }^{3}$

Nos rituais, podemos entrar em contato, muito diretamente, com aquilo que Marcel Mauss (2003) indicou como fundamental para uma apreensão mais integral do humano: a multiplicidade e simultaneidade de significados experimentados em uma mesma ação. Nunca conseguimos compreender uma atividade ritual em apenas uma clave de sentido; há sempre múltiplos sentidos sobrepostos. Há aspectos econômicos, políticos, jurídicos, morais, cognitivos, entre outros que ali se enfeixam. E há junto com isso tudo, muito frequentemente, a simultaneidade de linguagens expressivas - os rituais recorrem ao canto, à dança, à música, à plasticidade e aos gestos e encenações. Minhas pesquisas etnográficas abrangem o carnaval e os folguedos do boi no Brasil (e vale dizer que tanto as formas do carnaval como da brincadeira do boi são inúmeras e muito variadas), e o problema da simultaneidade de significados sempre se impôs de modo marcante. Experimentamos nessas festas populares, de modo característico e singular, uma multiplicidade de formas expressivas justapostas ao longo da duração da atividade ritual: música, dança, formas plásticas e visuais, eventualmente formas dramáticas - todas sobrepostas e interligadas no momento da realização. Com isso chegamos ao tópico central da temporalidade dos rituais. 


\section{A TEMPORALIDADE DOS RITUAIS - OS CALENDÁRIOS FESTIVOS}

O folclorista Arnold Van Gennep (2011 [1909]) distinguiu dois tipos de ritos de passagem: aqueles que pontuam a trajetória de vida de um indivíduo dentro de seu grupo social e aqueles que acompanham a passagem das estações ou as primeiras colheitas nas sociedades tradicionais e nos quais o grupo social é abarcado por inteiro. Estes últimos são os chamados ritos de calendário, ou seja, os rituais que acontecem dentro de um tempo social mais amplo estabelecido na forma dos nossos calendários.

O carnaval e os folguedos do boi são rituais de calendário, pois ocorrem em épocas distintas do ano, e com eles a passagem do tempo social ganha graça, intensidade e ritmo próprios. Nosso ano rotineiro - organizado na sequência dos dias, semanas e meses de um ano histórico datado, que segue sempre em frente - vê-se assim envolvido por um ciclo festivo que traz consigo visões de mundo abrangentes.

$\mathrm{Na}$ formação da sociedade brasileira, as brincadeiras e festas populares, como o carnaval e o folguedo do boi, encontraram abrigo no calendário cosmológico cristão cíclico que se repete no correr dos séculos. Esse calendário tem por referência a datação anual da Páscoa, pois sua montagem se articula em torno da morte e da ressurreição de Jesus Cristo. Os processos de sincretismo que produziram a riqueza e variedade da cultura popular brasileira ocorreram dentro dessa moldura temporal cristã ampla. Às tradições católicas portuguesas incorporaram-se assim aquelas que chegaram ao Brasil com as populações africanas escravizadas, as dos grupos indígenas e das diversas culturas trazidas pelos imigrantes das mais diferentes partes do mundo.

A passagem anual do tempo social pontuada pelos rituais ganhou ritmo coletivo característico, diminuindo morosamente ou se acelerando candente e trazendo consigo a experiência coletiva de emoções e sentimentos expressos de modo padronizado. O carnaval é um bom exemplo, pois associa-se à expressão da alegria, dos excessos, da agressividade. Ora, os estudiosos do carnaval são unânimes em ressaltar que o carnaval contrasta não só com o cotidiano, mas também com o período restritivo da quaresma, que imediatamente o sucede no calendário festivo cristão. Ilumina-se assim a oposição de sentido entre a transcendência da alma na vida eterna encenada pela quaresma e a afirmação do aqui e do agora, do corpo e da carne, celebrados pelo carnaval. A festa profana articula-se à temporalidade religiosa e deixa entrever sua complementariedade com outros momentos festivos desse calendário cosmológico amplo. 
Os folguedos do boi trazem à cena outra dimensão do calendário cristão, pois não se ligam diretamente ao ciclo da morte e ressureição de Cristo, mas sobretudo ao calendário das chamadas festas de santo, tradicionais no catolicismo brasileiro. Em toda a Região Norte do Brasil, as brincadeiras do boi vão-se aninhar dentro dos festejos devotados aos tradicionais santos juninos - Santo Antônio, São João, São Pedro e São Marçal. Já na Região Nordeste, os folguedos do boi se abrigaram no ciclo natalino, situado entre o Natal e o Dia de Reis. E, para complicar tudo isso, no Sudeste, no Espírito Santo e aqui no Estado do Rio de Janeiro, vamos encontrar o boi no ciclo carnavalesco! Os folguedos do boi se articulam e se movimentam no calendário festivo de modo muito diferente do que é próprio do carnaval.

Essa articulação dos rituais festivos populares com calendários de natureza cosmológica ampla os diferencia bastante das atividades teatrais propriamente ditas, cujo acontecimento pode dispensar esse tipo de inserção temporal.

\section{A TEMPORALIDADE INTERNA DOS RITUAIS. FLUXO E SEQUÊNCIA DE AÇÕES}

Os rituais, entretanto, constroem também sua própria temporalidade interna, como descobriu também o já citado folclorista Arnold Van Gennep. Sob esse aspecto, os rituais aproximam-se muito da experiência teatral, marcando também o início, o meio e o fim de sua própria duração e preenchendo-a sequencialmente com ações simbólicas e expressivas que obedecem a um desenrolar necessário.

Muitas manifestações da cultura popular apresentam formas artísticas características, com organização expressiva e estética bastante elaborada e assemelhada à de formas dramáticas: são sequenciais, seu desenrolar obedece a uma determinada ordem preconcebida, com começo, meio e fim necessários ao sucesso de sua realização. Esse é o caso do carnaval das escolas de samba e também dos folguedos do boi. Neles, sequências estipuladas de antemão devem suceder-se de modo fluente, caso contrário tudo arrisca perder-se.

A bateria de uma escola de samba deve recuar para a lateral da pista de desfiles, a um certo ponto do trajeto, de modo a prosseguir animando com seu poderoso ritmo o canto e a dança coletivos da escola que passa. O "grito de guerra" da escola deve acontecer ainda na concentração, quando ela se prepara para iniciar, com o potente canto do puxador do samba-enredo, o grande fluxo de sua passagem ritmada pela avenida. O mestre-sala e a porta-bandeira devem exibir seu nobre bailado de acordo com um repertório coreográfico e um código de etiqueta característicos, em momentos específicos, quando a escola pode deter seu 
movimento por alguns poucos minutos sem que sua evolução na passarela seja prejudicada. E, mesmo os passistas, que tendemos a associar a uma forma mais espontânea de expressão, executam sua dança segundo convenções e técnicas corporais bem definidas, que almejam produzir um certo efeito no espectador que os observa, geralmente maravilhado. Eles também devem seguir o fluxo da escola e nela se inserir de modo definido.

Nas performances do bumbá de Parintins (AM), almeja-se a construção de um clímax em certos momentos do ritual. Suas sequências dramáticas convergem sempre para o momento esfuziante em que um personagem devidamente caracterizado - o boi, seu amo, a sinhazinha da fazenda ou o pajé, por exemplo - emerge de modo surpreendente na arena festiva: desde dentro da boca de uma cobra grande alegórica que se abre subitamente ou de um coração alegórico que se parte em pedaços ao girar cada vez mais rapidamente lançando rastros de fogos de artifício no ar. $\mathrm{O}$ efeito almejado dessas surpresas guardadas sempre a sete chaves pelos grupos brincantes é o maravilhamento do espectador.

Há, em suma, nessas festas populares todo um trabalho organizado a partir de uma intenção artística, estética, que visa produzir efeitos nos brincantes e espectadores, assemelhada à das formas dramáticas. Com isso, no entanto, nesses contextos rituais, estaríamos falando exatamente de teatro e de drama? Ao chegar mais perto, as coisas sempre se complicam; como prosseguir esta conversa?

\section{APROXIMAÇÕES E AFASTAMENTOS ENTRE RITUAL E TEATRO. O DRAMÁTICO E O EXPRESSIVO NA CULTURA POPULAR}

Não só nas teorias de ritual de modo geral, mas também no universo mais específico das culturas populares é recorrente o uso de termos cuja matriz é teatral. Muito do vocabulário teatral foi e é utilizado para classificar e mesmo compreender o universo de algumas brincadeiras populares, frequentemente aproximado daqueles dos autos medievais ou das formas farsescas, das pantomimas, do teatro de revista. Com essas ideias deseja-se justamente indicar a presença de alguma formalização estético-expressiva de natureza dramática nos processos culturais populares. Eles apresentariam agregados de cenas, ligadas a algum tipo de roteiro, que se desenvolveriam de forma mais ou menos articulada.

A expressão auto popular é especialmente recorrente nos estudos de folclore, que com ela classificam diversos folguedos populares - como o bumba meu boi, a cavalhada, a marujada. Essa noção alude de modo frouxo ao teatro medieval, aos mistérios de cunho religioso e a apresentações em praça pública. Outra noção muito recorrente é aquela de danças dramáticas proposta por Mário 
de Andrade (1982), em que também a alusão a formas de expressão teatralizadas está presente. Andrade pretendia reunir um grande número de expressões populares sob essa denominação, que ressaltaria seu traço característico: o de serem sequências dançadas pontuadas por pequenas dramatizações justapostas como em uma suíte musical. No termo auto, não há a ideia da dança; já a noção de dança dramática articula a teatralização à dança. Essa atenção para a dança e o desejo de conceituar as formas expressivas populares conferem interesse especial à discussão de Mário de Andrade, à qual já dediquei um ensaio (CAVALCANTI, 2012). Porém importa aqui ressaltar que ambas as noções - auto ou dança dramática indicam a existência de algum tipo de roteiro ou enredo a ser encenado e que seria apresentado nas ocasiões festivas e rituais.

É justamente nesse ponto sutil - quando se supõe a existência de enredos mais ou menos fixados a desenvolver nas ocasiões festivas da cultura popular - que as coisas se complicam. Vejamos. Quando aproximamos no item acima os processos rituais populares do teatro, chamamos atenção para a moldura temporal que demarca a natureza excepcional dos primeiros, ordenados em uma sequência necessária de ações. A ideia de enredo, porém, traz um novo elemento a essa comparação, pois supõe a existência de algum texto de referência preexistente à encenação. Daí deriva a ideia de que na cultura popular, então, assim como nas formas teatrais eruditas, o dito enredo guiaria a performance conduzindo-a a seu desfecho, seja ele qual for. Ora, quando o que se retém da ideia de teatro é apenas essa ideia da encenação de um enredo (há um tema desenvolvido em enredo e encenado na manifestação popular), nosso entendimento dos processos culturais populares muitas vezes se turva. Vou dar dois exemplos de como tendo chegado tão perto, o ritual novamente se afasta do teatro, talvez para dele se reaproximar por outro caminho.

\section{AS ESCOLAS DE SAMBA}

A ideia de enredo é central para a compreensão do tipo de carnaval das escolas de samba, e todos a ela recorremos quando tratamos do assunto. Qual é, entretanto, a função desse enredo no desfile carnavalesco compreendido como uma ocasião ritual?

Um desfile carnavalesco tem sempre como ponto de partida de sua concepção a elaboração de um conjunto de ideias a ser tematizado em sua apresentação, o que chamamos de enredo. No entanto, o enredo carnavalesco está muito longe de corresponder a um entendimento mais estrito da noção de enredo que circula em outras formas artísticas. E apresso-me a esclarecer que é muito bom que seja assim, pois se assim não fosse não teríamos exatamente um carna- 
val! Num desfile de escola de samba, qualquer enredo proposto é literalmente carnavalizado - isto é, partido em pedaços, subvertido, transformado, deslocado pelas múltiplas linguagens expressivas, musicais, plásticas e rítmicas que a ele se agregam no ato vivo de sua realização sempre imprevisível.

O folclorista e antropólogo Edison Carneiro, quando se debruçou sobre o problema da conceituação dos processos culturais populares, ponderou, a meu ver com razão, que os folguedos populares não eram nem autos nem danças dramáticas, pois essas duas noções não indicariam adequadamente o que neles ocorre. Ele foi jurado do carnaval das escolas de samba em 1959, juntamente com Fernando Pamplona (que, professor da então Escola Nacional de Belas Artes, depois integrada à UFRJ, logo em seguida ingressaria como artista na escola de samba Salgueiro e renovaria o carnaval com estética e temática que podemos denominar afro-brasileira). 1959 foi um ano marcante no carnaval das escolas de samba, quando o casal Marie Louise e Dirceu Nery, trabalhando no Salgueiro, investiu na unidade estética dos diferentes elementos expressivos de um desfile. ${ }^{4}$ Edison Carneiro não concordava com a denominação danças dramáticas que Fernando Pamplona atribuiu certa feita às escolas de samba; para Carneiro, elas não teriam a forma da suíte indicada por Mário de Andrade e apresentariam, pelo contrário, "grande inteireza e unidade estrutural". ${ }^{5}$ Essa "unidade estrutural" está, creio eu, também na base da ideia do carnaval das escolas de samba como uma "ópera popular" apregoada pelo carnavalesco Joãozinho Trinta, nos anos 70 e 80, ideia que, por sua vez, ressoa até hoje, indicando que o enredo é encenado de forma múltipla com a dança, o canto e a visualidade plástica das escolas. Trata-se de aproximação metafórica que dá certamente a dimensão da grandeza e complexidade do espetáculo das escolas. Mas as escolas de samba não são óperas. Não há nelas personagens fictícios definidos e nem o encadeamento orgânico de ações dramáticas, mas há, é certo, um canto coletivo, porém dançante ou, melhor, "sambante"!

Qual é o problema que quero indicar? Aquilo que dizemos conscientemente que acontece em um processo cultural pode perder de vista muita coisa interessante do que realmente acontece. Quando deslocamos noções e conceitos de outros circuitos culturais para o universo popular, mesmo que com a meIhor das intenções de enaltecê-lo, corremos o risco de perder muito da singular complexidade dos processos culturais populares, que são arte, sim, mas, em nosso caso, uma arte de consumo ritual e elaborada em termos próprios. Um jurado vai julgar o carnaval, e o material de julgamento informa que a escola apresenta um enredo com todos os seus pontos de desenvolvimento, e que é isso que vai ser encenado pela escola quando ela desfilar na passarela. É um fluxo come- 
ço-meio-fim, 80 minutos para contar aquele enredo. Tudo parece estar resolvido, sem maiores mistérios, e a própria escola nos diz: "Olha, vamos contar esse enredo, e as alegorias vão representar isto e aquilo, e o samba-enredo se relaciona com o enredo desta ou daquela forma". É claro que tudo isso vale, tudo isso conta. Mas é fundamental ir além de um pensamento descritivo e observar que a relação do samba-enredo com o enredo propriamente dito não é uma relação direta: o samba-enredo, de partida, elabora apenas aspectos de um enredo, e o enredo propriamente dito abrange um universo muito mais amplo de imagens, referências e de alusões. O samba vai eleger apenas alguns aspectos. Ele é fruto de uma competição interna a cada escola, na qual se inscrevem as parcerias de compositores, e, ao longo do ano, jurados vão decidir qual samba se relaciona melhor com aquele enredo não só do ponto de vista estritamente musical, mas também como um samba que permitirá a integração da escola como um todo, um samba que a cada vez que se repita seja melhor de cantar. Quando o compositor minimalista Philip Glass veio ver os desfiles, lá nos idos de 1991, encantou-se com os sambas-enredo porque: "Eles repetem o tempo todo"! Essa repetição do mesmo samba inúmeras vezes, enquanto uma escola percorre a avenida, é um elemento decisivo para a evolução e harmonia do desfile de uma escola e tem um efeito totalmente transformador sobre o próprio significado da letra de um samba. 0 samba é cantado repetidamente enquanto a escola percorre a passarela em fluxo, e disso resulta o fato de que, no nível musical, há a insistência em apenas alguns tópicos do enredo, repetidos intensivamente com o samba. Porém, isso é só um aspecto da experiência ritual plena de um desfile, porque, junto com o canto, há o fluxo visual contínuo e linear do desfile na passarela que, obedecendo à sequencialidade do enredo, é mantido no plano visual e plástico. Quem está assistindo tem um ponto de vista fixo e vai ver em sequência os diferentes tópicos apresentados no desfile ouvindo repetidas vezes o mesmo samba. Assim é que a integridade da experiência vivencial de um desfile transforma por completo a relação supostamente direta entre enredo e encenação.

Além disso, fala-se que um carro alegórico ilustra o enredo ou vai elaborá-lo como uma espécie de âncora. No Carnaval de 1992, que serviu de base para meu livro Carnaval carioca: dos bastidores ao desfile (CAVALCANTI, 2006), o tema do enredo da Mocidade Independente de Padre Miguel era "Sonhar não custa nada", e esse enredo ordenava-se em 13 tópicos envolvendo o tema do sonhos, cada um deles a ser elaborado por um carro alegórico. Um deles era o sonho psicodélico, então nesse carro viriam elaborações dessa ideia com pílulas coloridas representando os alucinógenos e imagens multicoloridas aludindo aos delírios das viagens interiores. Numa visão mais linear, temos um carro alegórico que ela- 
bora esse tema, sucedido ou precedido por alas fantasiadas de acordo com aspectos desse tema. Dizemos então que aquele carro alegórico estaria exemplificando aquilo. Acontece que a relação entre o carro alegórico e o enredo (que mantêm obviamente um nexo de sentido básico) é efetivamente alegórica, ou seja, um carro alegórico traz sempre uma multiplicidade de imagens que abrem o tema inicialmente proposto pelo enredo para muitas outras cadeias de significado imprevistas. Na hora em que ele passa, aquele carro alegórico traz imagens que podem não ter sido elaboradas no enredo, mas que ali foram ligadas a ele. Por exemplo, no caso do tema da "Insônia", elaborado em outro carro, havia uma cama, um casal brigando, jogando travesseiros um no outro; atrás deles vidros gigantescos cheios de soníferos, atrás dos quais giravam rodas de carneirinhos. Havia a pessoa contando carneirinhos, os dois gigantescos potes de remédios, mosquitos que impediam as pessoas de dormir... Portanto, a relação entre o enredo que serviu como ponto de partida e sua realização propriamente dita na alegoria está também longe de ser direta. Isso significa que definir um desfile carnavalesco de uma escola de samba como a encenação de um enredo apreende apenas até certo ponto o que está em jogo, pois um desfile se liberta mesmo ali, na hora em que acontece... Essa é sua graça carnavalesca.

\section{OS FOLGUEDOS DO BOI}

Outro bom caso para refletir é o dos folguedos do boi. Um caso fascinante. Para essas manifestações convergiram as atenções modernistas, e Mário de Andrade foi um apaixonado pelos folguedos do boi, e sua visão sobre o folclore e a cultura popular influiu profundamente na gênese posterior das instituições culturais dedicadas ao folclore, na própria cultura popular e muito especialmente na visão que os estudiosos desenvolveram sobre esses assuntos (CAVALCANTI, 2012). Mário de Andrade (1982) considerava o bumba meu boi a dança dramática mais exemplar, original e também a mais estranha, de todos os folguedos. Pois justamente, Andrade acreditava que o aspecto central desses folguedos era a encenação do drama da morte e ressurreição do boi. Essas ideias foram expostas em seu texto sobre as danças dramáticas, que foi escrito entre 1933 e 1943, em diferentes versões. É um texto de leitura difícil porque é heteróclito, ele escreveu, reescreveu, adicionou partes, e somente pouco tempo antes de sua morte o considerou pronto

E o que aconteceu? Os pesquisadores, bem como as secretarias e as políticas públicas que se construíram depois, foram procurar nos folguedos do boi a encenação desse drama, e muitas vezes não encontraram... Então, qual é o diagnóstico? (que por sinal foi também o diagnóstico de Mário de Andrade nos anos 
40): o boi está em decadência! Moribundo diante dos avanços dos processos de modernização do país. Isso gera muita incompreensão acerca da maneira como a mudança social afeta a cultura popular e produz equívocos. Quando estudamos as brincadeiras do bumba meu boi de modo etnográfico, podemos perceber que a encenação da história da morte e ressurreição de um boi precioso - de uma trama, em suma - não se relaciona com o ritual de modo direto, mas em sentido muito diferente do que ocorre com as escolas de samba e o enredo em seu desfile. No caso dos folguedos do boi, essa trama simplesmente não é um enredo feito necessariamente para ser encenado. Não se trata de um roteiro, como numa forma teatral erudita; essa trama é um mito, uma narrativa mítica de origem do folguedo e não uma história que, encenada outrora, teria dado origem à brincadeira. A relação dessa trama com aquilo que de fato acontece em um contexto concreto da brincadeira do boi é muito frouxa. As formas da brincadeira do boi são muito variadas; muitas delas não têm encenação nenhuma, e isso não significa que estejam decadentes. Porém algumas modalidades do bumba meu boi, como o boi de zabumba maranhense, abrigam efetivamente tradições dramáticas cômicas que, na contemporaneidade, tendem a perder espaço diante das exigências das performances mais turísticas da capital do estado. Carvalho $(2011,2014)$ encontrou em suas pesquisas no interior do Maranhão a encenação de comédias, chamadas de "matanças" - histórias inventadas para a ocasião, que podem aludir ou não ao assunto da morte e da ressurreição do boi. Em certos momentos da performance de um grupo de brincantes, é possível haver uma sequência encenada por personagens devidamente caracterizados, mas não necessariamente a mesma coisa é feita para um público diverso e mais amplo.

É preciso apreender a riqueza, a fluidez e mesmo a falta de ordem, no bom sentido, dos processos populares. Mesmo quando os processos populares almejam, e alcançam, uma expressão estética elaborada, capaz de nos emocionar, eles dependem a cada vez de uma realização concreta e única. Correm sempre um risco: uma ideia pode dar certo e pode dar errado, um efeito idealizado pode não acontecer - como num desfile que achamos monótono, porque simplesmente "não funcionou" ou porque alguma coisa deu errado e "uma alegoria quebrou", atrapalhando a evolução da escola. Ou como em uma apresentação do bumbá de Parintins a que assisti em 2010, em que, por falta de tempo, uma belíssima alegoria não pôde "acontecer", isto é, movimentar-se, abrir-se trazendo os personagens-surpresa e depois desarticular-se e deixar a arena (CAVALCANTI, 2011). Então o imperfeito, o erro, a falha, em suma, o que foi feito para acontecer e não aconteceu é um aspecto intrínseco das formas da cultura popular aparentadas de algum modo com a teatralização. Mário de Andrade $(1982,1976)$ olhava a cultura 
popular com uma exigência estética fundamental, pois nela buscava um modelo que servisse para dar autenticidade à construção da própria cultura erudita nacional, e ele se impacientava quando alguma coisa dava errado, quando as coisas não aconteciam do jeito que deviam acontecer nem emocionavam como deveriam emocionar; quando alguma coisa falhava ou faltava, em suma.

É preciso integrar a dimensão da performance a nossa compreensão dos processos populares. A qualidade da realização em si, como vimos acima, muito frequentemente transforma aquilo que se idealiza acerca de uma determinada expressão popular. A noção de performance - oriunda tanto do campo das artes como de diversos campos de conhecimento, como a linguística, a chamada literatura oral, etnomusicologia e também da antropologia dos rituais - veio valorizar a temporalidade interna ao desenrolar de uma experiência, o compartilhamento por atores e espectadores de um mesmo momento, a presença direta e experimental como integrante de uma obra. Por esse outro caminho, novamente a área teatral e os estudos antropológicos dos rituais muito se reaproximam, e na obra de autores como Victor Turner (2008) essa mútua influência se evidenciou de modo notável (CAVALCANTI, 2013). Esse assunto por si só mereceria outra conversa.

Há muito assunto promissor para futuras conversas entre a antropologia e o teatro acerca da cultura popular. Mas sempre com esse cuidado de não deixar que a vivacidade dos processos populares arrisque a se empobrecer por conta de uma maneira predeterminada de olhá-los.

\section{NOTAS}

1 Esta é uma versão revista e ampliada da palestra apresentada no I Encontro de Teatro e Cultura Popular, realizada no Fórum de Ciência e Cultura (FCC)/UFRJ, em 2010, e transcrita no n. 12 da Série Passagens (FCC/UFRJ) em 2011.

2 Embora as noções de mito e de ritual estejam sempre inter-relacionadas, o estudo dos mitos seguiu curso próprio, ganhando ampla dimensão filosófica com a obra de Claude Lévi-Strauss, dedicada em grande parte a esse tema.

3 Por essa razão, compreendo a noção de festa e mesmo as teorias da festa (CAVALCANTI, GONÇALVES, 2010) como integrantes de campo teórico mais amplo abarcado pela noção de ritual.

4 Para um interessante enfoque do caráter moderno e inovador das escolas de samba entre os anos 30 e 40, ver Turano e Ferreira (2013).

5 Documentação do Arquivo Edison Carneiro, Biblioteca Amadeu Amaral, Centro Nacional de Folclore e Cultura Popular, Rio de Janeiro (RJ). 


\section{REFERÊNCIAS BIBLIOGRÁFICAS}

ANDRADE, Mário. O turista aprendiz. São Paulo: Livraria Duas Cidades/Secretaria da Cultura, Ciência e Tecnologia, 1976.

. Danças dramáticas do Brasil. Tomos I, II e III. Alvarenga, Oneida (Org.) São Paulo: Itatiaia/Instituto Nacional do Livro, 1982.

CAVALCANTI, Maria Laura Viveiros de Castro. Drama, ritual e performance em Victor Turner. Sociologia \& Antropologia, v. 03.06, p.411-439, jul.-nov. 2013. . Reconhecimentos. Antropologia, folclore e cultura popular. Rio de Janeiro: Ed. Aeroplano, 2012. 2011.

Alegorias em ação. Sociologia \& Antropologia, v. 01.01. p.233-249,

.Carnaval carioca: dos bastidores ao desfile. Rio de Janeiro: Ed. UFRJ. 3 ed. revista e ampliada, 2006.

. O boi-bumbá de Parintins: breve história e etnografia da festa. História, Ciências, Saúde - Manguinhos: visões da Amazônia. Rio de Janeiro: Fiocruz, v. 6 (suplemento especial nov.), p.1019-1046, 2000.

CAVALCANTI, Maria Laura V.C.; GONÇALVES, José Reginaldo (Org.). As festas e os dias: ritual, etnografia e análise cultural. Rio de Janeiro: Ed. Contracapa, 2010.

CARVALHO, Luciana Gonçalves de. A graça de contar. Um Pai Francisco no bumba meu boi do Maranhão. Rio de Janeiro: Editora Aeroplano, 2011.

(Org.). Comédias do bumba meu boi do Maranhão. Santarém: Cumbuca Norte, 2014.

DOUGLAS, Mary. Pureza e perigo. São Paulo: Ed. Perspectiva, 1976.

. O mundo dos bens. Para uma antropologia do consumo. Rio de Janeiro: Ed.UFRJ, 2004.

DAMATTA, Roberto. Carnavais, malandros e heróis. Por uma sociologia do dilema brasileiro. Rio de Janeiro: Zahar Ed., 1979.

GEERTZ, Clifford. Thick description: toward an interpretive theory of culture. In: The interpretation of cultures. New York: Basic Books, 1973a, p. 3-30.

. The impact of the concept of culture on the concept of man. In: The interpretation of cultures. New York: Basic Books, 1973b, p. 33-54.

GOFFMANN, Erving. A representação do eu na vida cotidiana. Petrópolis: Ed. Vozes, 1975.

HARRISON, Jane E.. Prolegomena to the study of greek religion. Cambridge: Cambridge University Press. Second Edition. Preservation Photo copy, 1991. Book Lab. Inc., 1908.

MAUSS, Marcel. Sociologia e antropologia. São Paulo: Cosac\&Naify, 2003.

SAHLINS, Marshall. Culture and practical reason. Chicago: The University of Chicago Press, 1976. 
TAMBIAH, Stanley. Culture thought and social action. An anthropological perspective. Cambridge: Harvard University Press, 1985.

TURANO, Gabriel; FERREIRA, Felipe. Incômoda vizinhança: a Vizinha Faladeira e a formação das escolas de samba no Rio de Janeiro nos anos 30. Textos EscoIhidos de Cultura e Arte Populares, v. 10, 65-92, 2013.

TURNER, Victor. Drama, campos e metáforas. Niterói: EdUFF, 2008.

VAN GENNEP, Arnold. Os ritos de passagem. Petrópolis: Ed. Vozes, 2011 [1909].

Maria Laura Viveiros de Castro Cavalcanti é professora do Departamento de Antropologia Cultural e do Programa de Pós-graduação em Sociologia e Antropologia do Instituto de Filosofia e Ciências Sociais da Universidade Federal do Rio de Janeiro. Autora de diversos livros e artigos, entre eles Carnaval carioca: dos bastidores ao desfile (Ed. UFRJ, 2006) e Reconhecimentos: antropologia, folclore e cultura popular (Ed. Aeroplano, 2012).

Recebido em: 09/09/2014

Aceito em: 22/10/2014 